\title{
STUDY ON In Vitro CONTROL OF Colletotrichum musae ISOLATED FROM RIPE FRUITS OF BANANA PHYTOEXTRACTS AND SELECTED FUNGICIDES
}

\author{
ARCHITA PRAKASH ${ }^{\mathrm{a} 1}$ AND PREETI PRASAD ${ }^{\mathrm{b}}$ \\ ${ }^{\mathrm{ab}}$ Department of Botany, Dr. B.R. Ambedkar Bihar University, Muzaffarpur, Bihar, India
}

\begin{abstract}
Colletotrichum musae the causal agent of anthracnose disease of banana fruit, was isolated from the diseased fruits and cultured in the laboratory. Six different culture media were tested for the selection of suitable culture medium. Both oat meal agar and Potato Dextrose Agar medium were found equally suitable for the above fungal pathogen. Six different medicinal plants were selected and leaf and clove extract at different concentrations were used. It was noted that $30 \%$ leaf extract of Nyctanthes arbourtis and Acasia nilotica exhibited $100 \%$ mycelial growth inhibition in vitro conditions. Actually all the phytoextracts had antifungal activities but their quantum of inhibition was less promising. In vitro experiments were also performed to determine the efficacy of seven commonly used fungicides at different concentrations. It was noted that at 2000 ppm four fungicides such as Difenconazole 25\% EC, Carbindazim 50\% WP, Benomyl 50\% WP and Mancozeb $75 \%$ WP completely inhibited the mycelial growth of the pathogen in vitro. Other fungicides also inhibited the radial growth, but the quantum of inhibition was less than the aforesaid fungicides at the same concentrations. To reduce the side effects of the chemical fungicides, alternative agents to control the fungal growth are essential. Selected phytoextracts may be the suitable candidate for the alternative of the chemical fungicides.
\end{abstract}

KEYWORDS: Anthracnose, Phytoextract, Radial growth, Fungicides, Colletotrichum musae, In vitro

Banana fruits are very popular in the world as it is delicious, cheap and easily available. There are different cultivars of banana but in Bihar Malbhog cultivar is more popular, delicious and liked by all next to Champa cultivar. In Bihar, farmers are now being attracted toward it and cultivation at commercial levels has started in different districts of the state among which, Hajipur of Vaishali, Muzaffarpur, Samastipur and Katihar are famous for the commercial cultivation. However, due to different diseases farmers get severe loss in the production. These diseases can be identified in the standing crops as well as in the storage of the fruits. Anthracnose disease, caused by the fungal pathogen Colletotrichum musae is most common that may be found on unripe and ripe banana fingers and hands. It becomes more alarming when the fingers and hands are severely infected in storage. This pathogen deforms the fingers and the hands and due to this the products are rejected by the customers, as such that the traders as well as the growers both face a heavy economic loss. In anthracnose disease the fungal spores infect the immature banana in field but symptoms appear later on. The symptoms can be noticed when the peel blemishes as black or brown, appearance of sunken spots of various sizes, on the fruits. These spots may bear several acervuli with their associated conidia on the fruit peel after ripening. Synthetic fungicides are being used to control the disease in post harvest storage. However, persistent use of fungicides has resulted in emergence of resistant strains of Colletotrichum musae. The residues of chemical fungicides may cause health problems, such as carcinogenic risk. So an alternative of chemical fungicides are essential. We are getting literatures where different fungal pathogens are being controlled by phytoextracts. Some of them may be mentioned here such as, Lin et al. (2002), Zhu et al. (2005), Lee et al. (2007), Mohana and Rabeesha (2007), Saha et al. (2008), Zake (2008), Dellavale et al. (2011), Saran Raj (2011), Thangamani et al. (2011), Shinde and Dhale (2011), Tapwal (2011), Bhardwaj (2012).

Gujar and Talwar (2012), Jagpat et al. (2013), Reddy et al. (2013), Sarode and Singh (2013), Sherwan et al. (2013), Kantwa et al. (2014), Jha et al. (2014), Hamza et al. (2015), Hussain et al. (2015), Gaine et al. (2016), Ghazanfar et al. (2016), Rani et al. (2016), Sharma et al. (2016), Devi et al. (2017), Kakralia et al. (2017), Kumar et al. (2017), Kumar and Singh (2017), Sahi et al. (2017), Wagh et al. (2017), Prasad et al. (2018). Keeping these ideas in mind the present work was carried to evaluate the efficacy of phytoextracts and selected fungicides to control the mycelial growth of Colletotrichum musae in vitro.

\section{MATERIALS AND METHODS}

Colletotrichum musae was isolated from the infected ripe banana fruits, which were collected from the storage of banana traders. The infected fruits were sterilized as describe in the standard text book of plant pathology and cultured in the Potato Dextrose Agar medium. Such infected parts were inoculated in the

${ }^{1}$ Corresponding author 
culture medium and on $10^{\text {th }}$ day the conidia were harvested and slides were prepared and microscopic study was done and based on its morphological features and conidial structure the pathogen was identified and pure culture was maintained in the laboratory. For the selection of suitable culture medium, the fungus was cultured in Potato Dextrose Agar medium, Cazpek's Dox Agar medium, Corn Meal Agar medium, Richard's Agar medium, Sabouraud's Agar medium and Oat Meal Agar medium. From the standard book of pathology the ingredients of the above media were weighed separately and dissolved in distilled water. The $\mathrm{pH} 6.5$ was adjusted and after autoclaving they were dispensed in culture plates. These plates were stored and used for inoculation. Based on the radial growth the selection of medium was done.

\section{PREPARATION OF PLANT EXTRACTS}

Healthy leaves of Datura metal, Psidium guajva, Lawsonia inermis, Phyllanthus niruri, were collected from the field and Cloves of Allium sativa, Rhizome of Curcuma longa were purchased from the markets. Well cleaned and dried leaves of above plants were weight separately. $100 \mathrm{~g}$ leaves of each plant were grinded in pre-cleaned and washed mortar in presence of $100 \mathrm{ml}$ sterile distilled water with the help of pestle. It was filtered through three layered muslin cloth. Final volume was made $100 \mathrm{ml}$ by adding fresh distilled water. Above filtrate was centrifuged in bench centrifuge at $4000 \mathrm{rpm}$ for 5-6 minutes. The supernatant was taken and used as stock solution. Similarly, the extracts from cloves of Allium sativa and rhizome of Curcuma longa were prepared. Potato Dextrose medium was prepared. Now form the above stock solution, the required volume was taken and added to that above medium was added to make the volume $100 \mathrm{ml}$ so that the culture medium had $10 \%, 15 \%$ and $20 \%$ concentrations of the plant extract. This was repeated for all the extracts separately.

The medium was allowed to solidify in which the inoculation was done. Here the technique used by Nene and Thapliyal (1993) was used. These culture plates were inoculated with the $7 \mathrm{~mm}$ disc of fungal mycelium, taken form 8 days old culture. With the help of presterilized cork borer of $7 \mathrm{~mm}$ diameter. Above disc was taken from the periphery of the plates where we get actively growing hyphae. The inoculation was done in aseptic condition of Laminar Air flow chamber and above disc was placed in the centre of the culture plate. These plates were incubated in culture rooms at $26 \pm 1^{\circ} \mathrm{C}$ temperature and $66-72 \%$ relative humidity. Plates without plant extract were also inoculated to be used as control.

Selected fungicides were also evaluated for their efficacy to control the radial growth of fugal mycelium in vitro. The fungicides used were:

\begin{tabular}{|c|c|}
\hline Common Name & Trade name \\
\hline Mancozeb & Dithane M-45 70\% WP \\
\hline Carbindazim 50\% WP & Bavistin 50\% WP \\
\hline Difenconazoel 25\% EC & Score \\
\hline Benomyle 50\% WP & Benlate \\
\hline Propinconazole & Tilt \\
\hline Thiophenate methyle & Roko \\
\hline
\end{tabular}

Above chemical fungicides were purchased form registered trader of Agrochemicals. These fungicides were weighed separately and standard solution was prepared so that their concentrations may be used as 1000 ppm, $1500 \mathrm{ppm}$ and $2000 \mathrm{ppm}$. They were also added in $100 \mathrm{ml}$ of PDA medium in such a way that their concentration became as above. Here also all the steps were taken as mentioned above, such as addition of fungicides, inoculation of fungal culture and incubation etc.

All the above experiments were done in triplicates and each time 15 cultures were used. The radial growth was calculated on $10^{\text {th }}$ day of inoculation. For this the plates were kept upside down. Now a line was drawn from the one end of periphery to other end. This gave the radial growth of the mycelium of the pathogen in treated and controlled conditions. The percentage of inhibition was calculated by using the formula:

$\mathrm{PI}=\mathrm{C}-\mathrm{T} / \mathrm{C} \mathrm{X} 100$

$\mathrm{PI}=$ Percentage of inhibition

$\mathrm{C}=$ Mycelial growth in control.

$\mathrm{T}=$ Mycelial growth in treated culture.

Mean of the data was tabulated and used for discussion and conclusion.

\section{RESULTS AND DISCUSSION}

Present work was aimed to control the radial growth of mycelium of Colletotrichum musae in the presence of different concentrations of six phytoextracts taken from six different commonly used medicinal plants and three different concentration of selected fungicides under in vitro. For the above experiments first of all six standard culture media for fungal pathogens were 
separately inoculated with the actively growing mycelial disc. The data obtained have been represented by the graph-1. It may be noted that radial growth of fungus on second, fourth, sixth and eight days of incubation in Potato Dextrose Agar medium was 40.64, 64.56, 85.78 and $90.46 \mathrm{~mm}$ respectively, which was the maximum radial growth in comparison to rest of the culture media used here. This was followed by the radial growth of the mycelium in corn meal agar medium, where the maximum radial growth was $88.54 \mathrm{~mm}$. It may be noted that lowest radial growth was in Sabouraud's agar medium which was $79.84 \mathrm{~mm}$ on $8^{\text {th }}$ day of inoculation. Next to this was Richard's agar medium where the radial growth was $81.24 \mathrm{~mm}$ and in Czapek Dox Agar 82.66 $\mathrm{mm}$. Therefore, from the graph it was concluded that maximum radial growth of Colletotrichum musae was in Potato Dextrose agar, followed by Oat meal agar medium, Corn meal agar and Czapek's agar medium. On Potato Dextrose Agar medium the colony was whitish to pale red, and similar colour was noted o the Cazpek's agar, Corn meal agar, media. On Oat meal agar the colour was grayish to pink in colour. Similarly, on Richard's and Sabouraud's medium the fungus produced grayish brown colonies. Above findings are in agreements with the findings of Lime et al. (2002) and Thangamani et al. (2011).

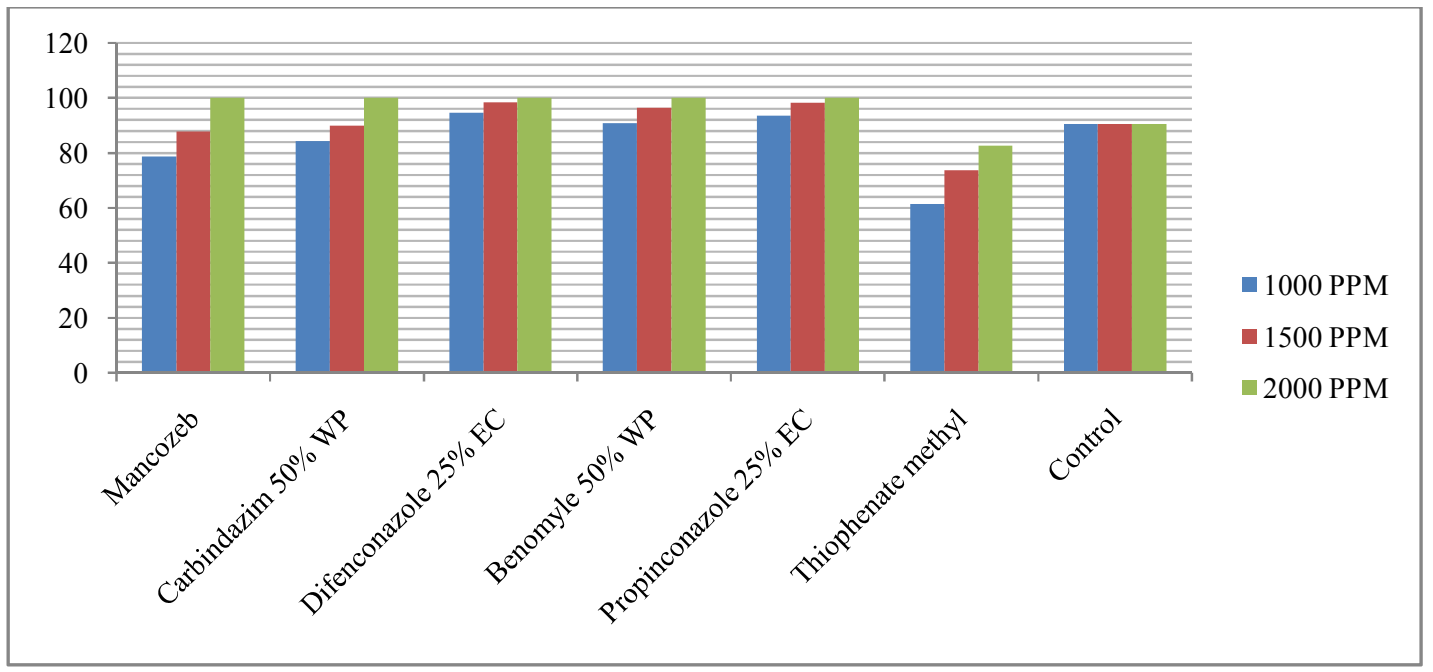

Graph 1: Impact of three concentrations of selected fungicides on radial growth of Colletotrichum musae In vitro

In the present work, six different plants were taken and aqueous extracts were prepared from their leaves and cloves \& rhizome. These extracts were used separately at three different concentrations to evaluate their fungitoxic effects. The data obtained are represented by the graph 2 .

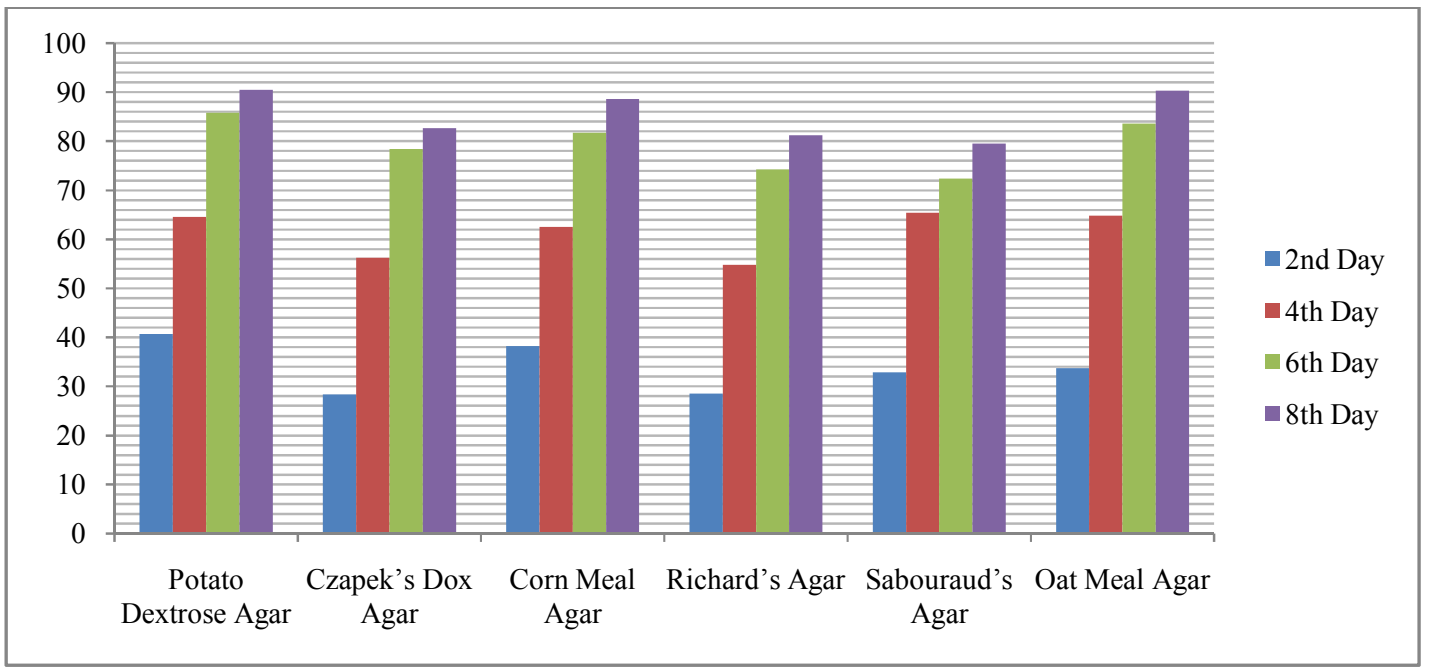

Graph 2: Effect of different media on radial growth of Colletotrichum musae 
From the graph, it was found that, extract taken from the cloves of Allium sativum could inhibit the radial growth at different concentration such as at $10 \%$ the inhibition was $64.54 \%$, at $15 \% 81.32 \%$ and at $20 \%$, $92.56 \%$ which was the maximum inhibition in comparison to the phytoextracts taken from other plants. At the similar concentrations the inhibition percentage in case Curcuma longa rhizome extracts was 63.38, 79.85 and 91.76 respectively. Here again it was noted that minimum inhibition was found in case of Phyllanthus niruri where the percentage of inhibition was 57.82, 70.48 , and 78.18 respectively. The extracts taken form Lawsonia inermis could inhibit the radial growth of the pathogen at the similar concentration that was 63.46 , 80.45 and 91.28 respectively. It may be concluded that though none of the phytoextracts used here could completely inhibit the radial growth at any concentrations, however, a considerable percentage of inhibition was noted in some of them. The inhibitory effect differed here may be due to the presence of different concentrations of antifungal secondary metabolites. Findings of the present work corroborate with the findings of Zhu et al. (2005), Mohana and Raveesha (2007), Venkataswamy et al. (2010), Dellavalle et al. (2011), Bhardwaj (2012), Serawani et al. (2013), Jha et al. (2014). Such plant extracts therefore, if used to control the fungal pathogen would be cheaper and ecofriendly.

Evaluation of efficacy of fungicides in vitro against any fungal pathogen gives us preliminary information regarding their impact on the fungal growth at a particular concentration. This may utilized when the aforesaid fungicide is to be used in field conditions. In the present work food poison technique was used and three different concentrations of six fungicides were evaluated in vitro for their efficacy. It was clear from the data represented by the graph -3 , that Difenconazole $25 \%$ EC at all the three concentrations revealed maximum percentage of inhibition of the radial growth of Colletotrichum musae, than rest of the fungicides at the similar concentration. This was followed by the percentage of inhibition in case of Propinconazole $25 \%$ EC.

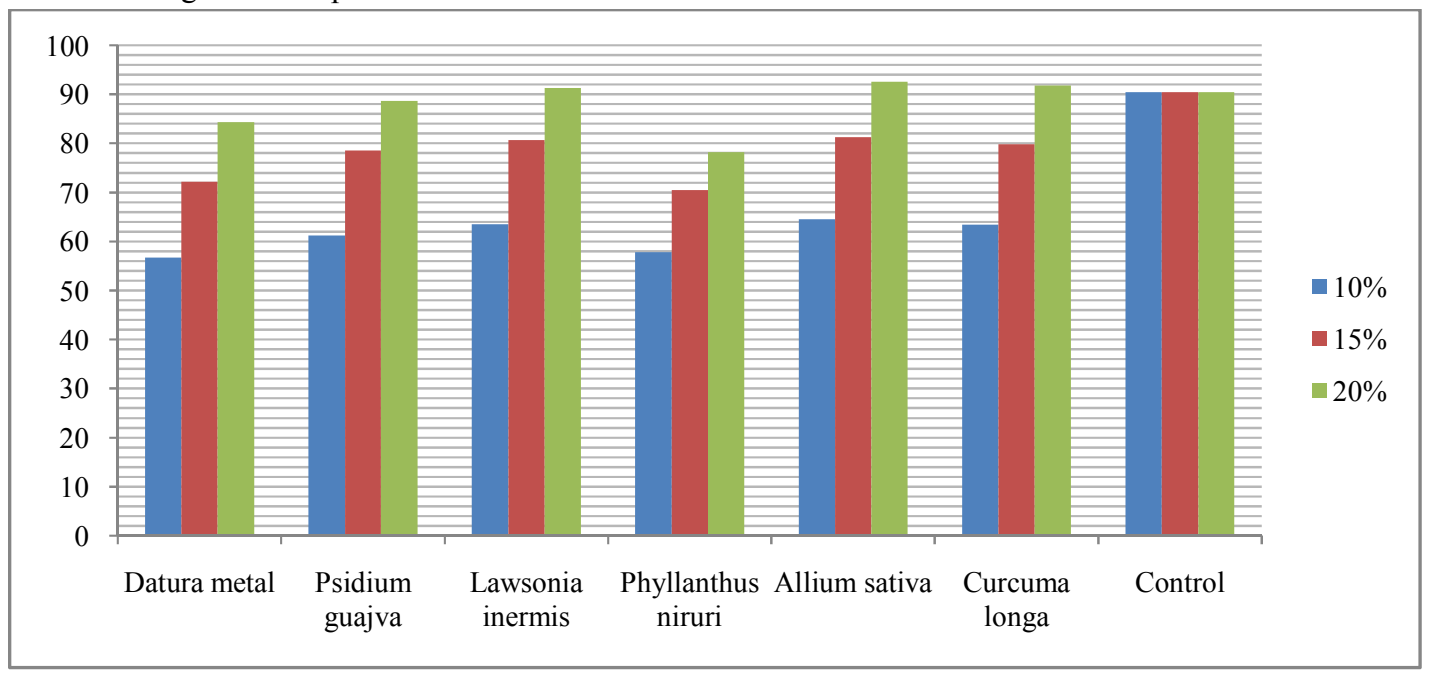

Graph 3: Showing impact of different phytoextracts at three different concentrations on radial growth of $C$. musae, In Vitro

It was further noted that at $2000 \mathrm{ppm}$ of Mancozeb, Carbindazim, Difenconazole 25\% EC, Benomyl 50\% WP and Propinconazole 25\% EC, the radial growth was completely inhibited. Minimum inhibition of radial growth of the fungus was noted in all the concentrations of Thiophenate methyl. Above findings are in agreement with the findings of Waghe et al. (2015), Ghazanfar et al. (2016), Theja Kuamr and Devappa (2016), Kumar et al. (2017), Shinde et al. (2017), and Hussain et al. (2018).
It may be concluded that selected phytoextracts may be used as an alternative agent for the chemical fungicides. This will be cost effective and no nontarget organisms shall be killed. Further pollution load of soil water shall be reduced. Similarly, if there is confirmation of a particular fungicide and its concentrations to control a particular disease, it will also support the farmers and their extra expenditures on unwanted fungicides at excess concentrations can be reduced. 


\section{ACKNOWLEDGEMENT}

The authors gratefully acknowledge the Head of Department of Botany, Dr. B.R.A. Bihar University, Muzaffarpur for providing facilities during this research work.

\section{REFERENCES}

Bhardwaj S.K., 2012. Evaluation of plant extracts as antifungal agents against Fusarium solani (Mrt)sacc. World J. Agric. Sci., 8: 385-388.

Dellavalle P.D., Cabrera A., Alam D., Patricia L., Fernando F. and Riza M.D., 2011. Antifungal activity of medicinal plants extracts against phytopathogenic fungus, Alternaria sp. C. J.A. Res., 71(2): 231-239.

Devi O.N., Singh N.I., Devi R.K.T. and Chanu W.T., 2017. In vitro evaluation of Alternaria solani (Ellis and Mart) causing fruit rot of tomato by plant extracts and bio-control agents. Int. J. Curr. Microbiol. App. Sci., 6(11): 652-661.

Ganie S.A., Ghani M.Y., Hussain A. and Ahangar F.A., 2016. Perpetuation of Alternaria solani of Potato under temperate Kashmir Valley condition. Molecular Plant Breeding, 7(25): 1-8.

Ghazanfar M.U., Raza W., Ahmed K.S., Qumar J., Haider N. and Muhmad H.R., 2016. Evaluation of different fungicides against Alternaria solani (Ellis \& Martin) Sorauer caused of Early blight of tomato under laboratory conditions. Int. J. of Zool. Studies, 1(5): 08-12.

Gujar J. and Talwar D., 2012. Antifungal potential of crude plant extract on some pathogenic fungi. World Journal of Science and Technology, 2: 58-62.

Hamza A.M., Mohmed A.A.A. and Derbalah A.S., 2015. Recent trends for Biocontrolling the tomato late blight disease under field conditions. Egyptian Journ. of Biol. Pest Control, 25(1): 145-151.

Hussain F., Abid M., Saukat S.S., Farzan and Akbar M., 2015. Antifungal activity of some medicinal plants on different pathogenic fungi. Pak. J. Bot., 47(5): 2009-2013.

Hussain S., Ayub M., Rasheed M., Hussain S., Hussain K., Hussain S.I., Hassan M., Hassain A., Hussain T., Imtiyaz M., Hussain A., Hussain S. and Riaz M., 2018. Efficacy of different fungicides against Alternaria tusi cause leaf blight of peas was first time discovered form Kharmang Olding and Skardu Baltistan. J. Entomology and Zoology Studies, 6(5): 22502260 .

Jagpat G.P., Mali A.K. and Dey U., 2013. Bioefficacy of fungicides, biocontrol agents and botanicals against leaf spot of turmeric incited by Colletotrichum capsici. African Journ. of Microbiol. Res., 7(18): 1865-1873.

Jha R., Roshan R., Sobita L., Simon and Lal A.A., 2014. Effect of six plant extracts on mycelial growth of Alternaria alternata causing leaf spot of Aloe vera. Int. J. of Res., 1(7): 1371-1373.

Kakraliya S.S., Choskit D., Pandit D. and Abrol S., 2017. Effect of bio-agents, Neem leaf extract and fungicides against Alternaria leaf blight of wheat (Triticum aestivum L.). Nat. Prod. Chem. Res., 5(8): 01-07.

Kantwa S.L., Tetarwal J.P. and Shekhawat K.S., 2014. In vitro effect of fungicides and phytoextracts against Alternaria alternata causing leaf blight of groundnut. Journal of Agricult. And Veter. Sci., 7(6): 28-31.

Kumar P. and Singh S., 2017. In vitro evaluation of fungicides and plant extract against Alternaria solani (Ellis) causing early blight in tomato (Lycopersicon esculentum). Int. J. Curr. Microbiol. App. Sci., 6(9): 820-827.

Kumar V., Singh G. and Tyagi A., 2017. Evaluation of different fungicides against Alternaria leaf blight of tomato (A. solani). Int. J. Curr. Microbiol. App. Sci., 6(5): 2343-2350.

Lee S.H., Chang K.S., Su M.S., Huang Y.S. and Jang H.D., 2007. Effects of some Chinese medicinal plant extracts on five different fungi. Food Control, 18: 1547-1554.

Lin J., Lin T.H. and Cha B., 2002. Isolation and identification of Colletotrichum musae form imported banana. J. Agric. Biol., 2: 361-363.

Mohana D.C. and Raveesha K.A., 2007. Antifungal evaluation of some plant extracts against some plant pathogenic field and storage fungi. Journ. of Agricul. Technol., 4: 119-137. 
Nene Y.L. and Thapliyal P.N., 1993. Fungicides in plant disease control. IIIed. Oxford and IBH Publishing company Pvt. Ltd. Callots Page 531.

Rani N., Lal H.C., Kumar P., Ekka S. and Kumar N., 2016. In vitro evaluation of fungicides, bioagents and plant extracts against Alternaria sp. infecting pigeon pea. Int. J. Curr. Microbiol. App. Sci., 7: 5112-5118.

Reddy R.R., Krishna K.C., Lokantha O., Mamtha S. and Reddy C.D., 2013. Antimicrobial activity of Azadirachta indica leaf, bark and seed extracts. Int. J. Res. Phytochem. Pharmacol., 3(1): 1-4.

Saha D., Dasgupta S. and Saha A., 2008. Antifungal activity of some plant extracts against fungal pathogens of Tea (Camellia sinensis). Pharmaceutical Biology, 43: 87-91.

Sahli N., Sultan A.M.S., Terzi V., Imran B. and Besati S., 2017. Antifungal activity of aqueous extracts of some dominant Algerian Medicinal plants. Biomed. Res. Int., 17: 1-6.

Saran Raj P., 2011. Pharmacological screening of Datura metal and Acalypha indica for its antifungal activity against pathogenic fungi. Int. J. Pharmaceut. Sci. Health Care, 1: 38-44.

Sarode R.S. and Singh P., 2013. Antifungal evaluation of Calotropis leafy extracts against some plant pathogenic fungi. Trends in Biosci., 6(1): 82-85.

Sharma H., Yunus G.Y., Agarwal R., Kalara M., Verma S. and Battar S., 2016. Antifungal efficacy of three medicinal plants Glycyrrhiza glabra, Ficus religiosa and Plantago major against Candida albicans: A comparative analysis. Ind. J. Dent. Res., 27(4): 433-436.

Sherwani S.K., Bokhar T.Z., Azim K., Gilani S.A., Kazmi S.U., 2013. Qualitative phytochemical screening and antifungal activity of Carica papaya leaf extract against human and plant pathogenic fungi. Int. Res. J. of Pharmacy, 4(7): 83-86.

Shinde V. and Dhale D.A., 2011. Antifungal properties of extracts of Ocimum tenuiflorum and Datura stramonium against some vegetable pathogenic fungi. Journal of Phytology, 3(12): 41-44.

Tapwal A., Garg N., Gautam N. and Kumar R., 2011. In vitro antifungal potency of plant extracts against five phytopathogenic. Brazilian Archieves of Biology and Technology, 54: 1093-1098.

Thangamani P., Kuppuswamy P., Peeran M., Gandhi K. and Raghuchander T., 2011. Morphological and physiological characterization of Colletotrichum musae the causal organism of banana anthracnose. World J. Agric. Sci., 7(6): 743-745.

Theja Kumar M.B. and Devappa V., 2016. Efficacy of different fungicides against Alternaria alternata and Cercospora capsici under in vitro conditions. Int. J. of Adv. Res. in Biol. Sci., 3(5): 126-129.

Venkataswamy R., Doss A., Sukumar M. and Mubarak H.M., 2010. Preliminary phytochemical screening and antimicrobial studies of Lantana indica Roxb. Ind. J. Pharm. Sci., 72: 229-231.

Wagh S.S., Suryawanshi A.P. and Pawar D.V., 2017. Efficacy of fungicides, bioagents and phytoextracts against Alternaria carthami of Safflower in in vitro condition. J. of Pure and Appl. Microbiol., 11(3): 1589-1598.

Zare Z., Ahmad M., Saffari T.N., Alireza I., Sedigne M., 2012. Antimicrobial activity of leaf and flower extract of Lippia nodiflora (Verbenaceae). J. of Plant Protect. Res., 52(4): 01-03.

Zhu X.F., Zhang H.X. and Lo R., 2005. Antifungal activity of Cynara scolymus L. extract. Fitoterasia, 76: 108-111. 